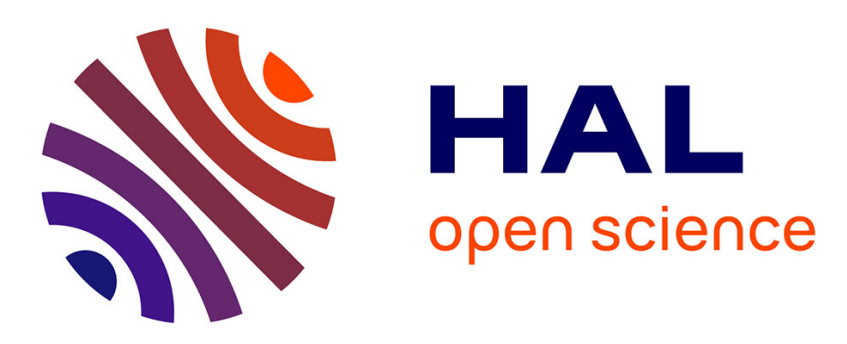

\title{
Ordering of C-terminal loop and glutaminase domains of glucosamine-6-phosphate synthase promotes sugar ring opening and formation of the ammonia channel.
}

\author{
Stéphane Mouilleron, Marie-Ange Badet-Denisot, Beatrice \\ Golinelli-Pimpaneau
}

\section{To cite this version:}

Stéphane Mouilleron, Marie-Ange Badet-Denisot, Beatrice Golinelli-Pimpaneau. Ordering of Cterminal loop and glutaminase domains of glucosamine-6-phosphate synthase promotes sugar ring opening and formation of the ammonia channel.. Journal of Molecular Biology, 2008, 377 (4), pp.117485. 10.1016/j.jmb.2008.01.077 . hal-00267138

\section{HAL Id: hal-00267138 \\ https://hal.science/hal-00267138}

Submitted on 9 Jul 2021

HAL is a multi-disciplinary open access archive for the deposit and dissemination of scientific research documents, whether they are published or not. The documents may come from teaching and research institutions in France or abroad, or from public or private research centers.
L'archive ouverte pluridisciplinaire HAL, est destinée au dépôt et à la diffusion de documents scientifiques de niveau recherche, publiés ou non, émanant des établissements d'enseignement et de recherche français ou étrangers, des laboratoires publics ou privés. 
Ordering of C-terminal loop and glutaminase domains of glucosamine-6P synthase promotes sugar ring opening and formation of the ammonia channel.

Stéphane Mouilleron ${ }^{1,2,3^{*}}$, Marie-Ange Badet-Denisot ${ }^{2}$, Béatrice Golinelli-Pimpaneau ${ }^{1}$

${ }^{1}$ Laboratoire d'Enzymologie et Biochimie Structurales, Bâtiment 34 et ${ }^{2}$ Institut de Chimie des Substances Naturelles, CNRS, 1 avenue de la Terrasse, 91190 Gif-surYvette, France, ${ }^{3}$ Present address: Structural Biology Laboratory, Cancer Research UK, London Research Institute, 44 Lincoln's Inn Fields, London WC2A 3PX, United Kingdom

Corresponding author: Béatrice Golinelli-Pimpaneau, tel: 3316982 42 35, fax: 33 1698231 29, e-mail: beatrice.golinelli@lebs.cnrs-gif.fr

Keywords: ammonia channel, glutamine amidotransferase, glucosamine-6-P synthase, conformational change, loop ordering, domain ordering, sugar ring opening Abbreviations: Fru6P, D-fructose-6-phosphate; Glc6P, glucose-6-phosphate; GlcN6P, glucosamine-6-phosphate; GImS, glucosamine-6-phosphate synthase, ${ }^{\mathrm{C}} \mathrm{GImS}$ synthase domain of glucosamine-6-phosphate synthase.

Running title: sugar ring opening in GImS

*Financial support from ICSN to one of us (SM) is gratefully acknowledged. 


\section{Summary}

Glucosamine-6-phosphate synthase (GImS) channels ammonia from glutamine at the glutaminase site to fructose-6P (Fru6P) at the synthase site. E. coli GImS is composed of two C-terminal synthase domains that form the dimer interface and two N-terminal glutaminase domains at its periphery. We report here the crystal structures of GImS alone and in complex with the glucosamine-6P product at 2.95 and $2.9 \AA$ resolution, respectively. Surprisingly, although the whole protein is present in this crystal form, no electron density for the glutaminase domain was observed, indicating its mobility. Comparison of the two structures with that of the previously reported GImS Fru6P complex shows that, upon sugar binding, the C-terminal loop, which forms the major part of the channel walls, becomes ordered and covers the synthase site. The ordering of the glutaminase domains likely follows Fru6P binding by the anchoring of Trp74, which acts as the gate of the channel, on the closed Cterminal loop. This is accompanied by a major conformational change of the sidechain of Lys $503^{\#}$ of the neighboring synthase domain that strengthens the interactions of the synthase domain with the C-terminal loop and completely shields the synthase site. The concomitant conformational change of the Lys $503^{\#-G l y 505^{\#}}$ tripeptide places catalytic His504 ${ }^{\#}$ in the proper position to open the sugar and buries the linear sugar, which is now in the vicinity of the catalytic groups involved in the sugar isomerization reaction.

Together with the previously reported structures of GImS in complex with Fru6P or glucose-6P and a glutamine analogue, the new structures reveal the structural changes occurring during the whole catalytic cycle. 


\section{Introduction}

Glucosamine-6P synthase $(\mathrm{GlmS})$ is a glutamine amidotransferase involved in the first step in hexosamine metabolism ${ }^{1}$. It catalyzes the conversion of D-fructose-6phosphate (Fru6P) into D-glucosamine-6P (GlcN6P) using glutamine as a nitrogen donor. GImS consists of a $27 \mathrm{kDa}$ N-terminal glutaminase domain (residues 1-239) that catalyzes glutamine hydrolysis and a $40 \mathrm{kDa}$ C-terminal synthase domain ( ${ }^{\mathrm{C}} \mathrm{GImS}$, residues 249-608) that catalyzes Fru6P amination and isomerization. The two active sites are linked by a $18 \AA$-long ammonia channel. The enzyme is functional as a homodimer, with two synthase domains forming the dimer interface. GImS obeys an ordered bi-bi mechanism with Fru6P binding preceding glutamine binding and release of glutamate followed by release of GlcN6P ${ }^{2,3}$. The structures of GImS in complex with Fru6P or with both glucose-6P (Glc6P) and glutamine analogue 6-diazo-5-oxo-L-nor-leucine (DON), which represent the states with one or two bound substrates, respectively, have previously elucidated the mechanism of catalytic activation resulting from glutamine binding ${ }^{4,5}$. In particular, the ammonia channel opens through a rotation of the indole group of Trp74, and the catalytic Cys 1 and Asn98 residues are repositioned to fulfill their catalytic roles of nucleophile and oxyanion hole, respectively. These changes are accompanied by a large hingebending rotation of the glutaminase domains relative to the synthase domains. We now report the crystal structures of GImS alone and in complex with GlcN6P, which represent the initial state of the enzyme and the final intermediate in the catalytic pathway, respectively. By comparison to the structure of the GImS.Fru6P complex ${ }^{4}$, these structures reveal the conformational changes occurring at the synthase active site upon Fru6P binding or GlcN6P release, therefore completing our view of the structural mechanisms occurring during the catalytic cycle. 


\section{Results}

\section{The glutaminase domains are mobile in the GImS and GImS.GIcN6P rhombohedral crystals.}

For both the GImS and GImS.GIcN6P crystals, we first tried to locate one monomer of GImS in the asymmetric unit, using either the whole protein or each domain of the GImS.Fru6P complex (PDB code 2BPL) as search models in the molecular replacement with $P H A S E R{ }^{6}$. Since attempts to position a glutaminase domain remained unsuccessful, the refinement of the synthase domain alone was directly carried out with REFMAC5, using as start model the structure of ${ }^{\mathrm{C}} \mathrm{GImS}$ in complex with GlcN6P (PDB code $1 \mathrm{MOQ}{ }^{7}$ ), which belongs to the same H32 space group as the GImS and GImS.GlcN6P structures. At the end of refinement (Table 1), no electron density could be observed for the glutaminase domain although the crystallographic packing indicates a large unoccupied volume that could accommodate it (Fig. 1A). Actually, the solvent content of the crystal, calculated without taking into account the glutaminase domains, is very high $(71.5 \%)$ and that for the whole enzyme $(52.4 \%)$ is a common value for proteins. To check that the crystallized protein is really whole GImS and not a proteolytic fragment corresponding to ${ }^{C}$ GImS alone, the content of the crystals was analyzed on SDS-PAGE (Fig. 1B). Comparison to a sample of GImS after purification indicates that the crystals contain the whole protein. This is in agreement with the relatively fast rate of crystal growth and the lower resolution of the GImS and GImS.GlcN6P structures (2.95 and $2.9 \AA$, respectively) compared to that for the ${ }^{C}$ GImS.GIcN6P structure $(1.57 \AA)^{7}$. Therefore, the glutaminase domains are present but disordered in the GImS and GImS.GIcN6P 
crystals. The synthase domains are involved in 1.56 and 1.58 crystallographic contacts per residue in the rhombohedral crystal forms of the GImS and GImS.GlcN6P structures, respectively, similar to what is observed for the previously determined GImS.Fru6P and GImS.GIc6P.DON structures belonging to different space groups ${ }^{5}$

\section{Analysis of sub-domain displacements in the crystals.}

After isotropic refinement of the GImS and GImS.GlcN6P structures, two subdomains, which correspond to the two topogically identical sub-domains forming the synthase domain ${ }^{8}$, were noticed to have very different B-factors (Fig. 2A and B). Therefore, these two sub-domains were used as different TLS groups in anisotropic refinement. TLS refinement yields translation, libration (torsional vibration) and screw tensors for each TLS group chosen, which describe its displacements in the crystal, and coordinates and residual individual $B$ factors for each atom. An anisotropic motion is indicated when the eigenvalues of the tensor (which represent the magnitude of displacement around three perpendicular axes) have different magnitudes around the three axes. While the TLS refinement does not indicate a particularly large nor anisotropic libration motion of subdomains 1 and 2 of the GImS or GImS.GlcN6P structures (mean-square displacements of 2.6-3.4 $\AA^{\circ 2}$ ), a relatively large rigid-body translational motion of subdomain 1 is observed (Fig. 2C). Indeed, the mean-square translational displacements are 0.376 and $0.285 \AA^{2}$ for subdomains 1 of the GImS and GImS.GlcN6P structures, respectively, which is higher than the estimated value of $0.165 \AA^{2}$ for a domain of this size ${ }^{9}$. The large rigid-body translational motion of subdomain 1 is consistent with subdomain 1 being linked to the mobile glutaminase domain. 
In the absence of sugar, the C-terminal loop is disordered and the synthase site is accessible to solvent.

The structure of free GImS reported here (Table 1) is the first structure of GImS with an open conformation of the synthase site, which confirms that GImS still behaves as a dimer in the absence of sugar and indicates that residues 602 to 608 of the $\mathrm{C}$ terminal nonapeptide (C-tail, residues 600-608) are mobile (Fig. 3A).

In the GImS.GlcN6P structure, the C-tail covers the synthase site (Fig. 3A). This structure is very similar to that of ${ }^{C}$ GImS in complex with GlcN6P ${ }^{7}$ (PDB code 1MOQ) (Fig. 3B), which belongs to the same space and has the same cell parameters and lattice interactions. This indicates that the interactions observed in the isolated synthase domain are independent on the absence or presence of the glutaminase domain and validates the conclusions made on the isolated synthase domain for the whole enzyme.

Since the C-tail is disordered in the GImS structure but ordered both in the GImS.GIcN6P and GImS.Fru6P structures ${ }^{4,8}$, we can conclude that the C-tail becomes ordered upon sugar binding in E. coli GImS.

\section{Discussion}

The previously reported structures of ${ }^{\mathrm{C}} \mathrm{GImS}{ }^{7,10}$ or whole GImS ${ }^{4,8}$ have shown the protein with a closed conformation of the synthase site. Indeed, the C-tail covers the synthase site when a sugar is bound ${ }^{4,7}$ (Fig 3C). The C-tail has been shown to form the major part of the channel and contains catalytic Lys603, which was proposed to form a Schiff base with the C2 carbonyl group of fructose-6P in the first step of catalysis to facilitate amination by ammonia ${ }^{11}$. In addition, the main-chain backbone 
of the Lys503-His504-Gly505 tripeptide (His-loop) of the neighboring synthase domain contributes to the sugar-binding pocket. The His-loop contains catalytic His $504^{\#}$, which has been proposed to be involved in the ring opening of Fru6 ${ }^{10}$. Finally, the glutaminase domain, when present, is also involved in the closure of the synthase site via the indole group of Trp74. Yet, the synthase site has to be open for binding Fru6P and it was anticipated that the C-tail should move away in the free enzyme ${ }^{8}$. The other scenario to open the synthase site involving a movement of the His-loop was predicted to be unlikely since this would have destroyed the dimer interface, which is energetically costly ${ }^{8}$. The structure of free GImS reported here allows to probe experimentally these different hypotheses.

\section{Conformational changes at the synthase site upon sugar binding.}

Comparison of the GImS, GImS.Fru6P and GImS.GIcN6P structures indicates that in E. coli GlmS, the C-tail becomes ordered upon sugar binding and covers the synthase site. This is different from what is observed in the crystal structures of the synthase domain of $C$. albicans glucosamine-6P synthase, Gfa1p, in which the C-tail as well as the five preceding residues (595-599) remain disordered in the presence of several different ligands ${ }^{12}$. In Gfa1p, the synthase active site is more open than that of E. coli and the His-loop is either disordered or has a very different conformation compared to that in GImS. In GImS, residues 498-502 preceding the His-loop interact with the main chain of helix CE (which follows the His-loop and is replaced by a loop in Gfa1p) through four $\mathrm{H}$-bonds and hydrophobic interactions so that, in Gfa1p, their disorder is probably linked to the disorder of the His-loop and the absence of the CE helix. The residue following the His-loop is an isoleucine in Gfa1p (instead of a proline in GImS) and the residue that makes a salt bridge with the lysine 
residue of the His-loop in GImS (Glu535 ${ }^{\#}$ ) is not conserved (GIn638 ${ }^{\#}$ in Gfa1p), which likely contributes to the flexibility of the His-loop in Gfa1p. In Gfa1p, the observed binding mode of cyclic Glc6P leaves no room for the imidazole ring of the catalytic histidine to bind like in GImS. Therefore, it was suggested that the ordering of the Ctail in Gfa1p might be required for the positioning of the sugar in a conformation in which the catalytic histidine could open the sugar ring ${ }^{12}$.

\section{The ordering of the glutaminase domains likely follows the closure of the C-tail}

\section{on the synthase site in GImS.}

Attempts to crystallize free GImS in the conditions of the GImS.Fru6P complex, in which the glutaminase domains are ordered, remained unsuccessful (data not shown), suggesting that the glutaminase domains cannot become ordered in the absence of sugar. Moreover, the glutaminase domains are not involved in crystal contacts in the rhombohedral form, which is likely to reflect what is happening in solution. Therefore, the observed mobility of the glutaminase domains is likely functionally relevant and may even be a necessary condition for the function of free enzyme.

The synthase domains contribute to most of the crystallographic contacts in the GImS.Fru6P and GImS.GIc6P.DON structures (Fig. 1 and Table 1B in ${ }^{5}$ ). In these structures, there are respectively three and two copies of the monomer in the asymmetric unit, which display different crystal contacts. The comparison of these different copies allows to differentiate the contacts that are important for function from those that vary with the crystal environment. The only crystallographic contacts of the glutaminase domain, which are found in all copies of the GImS.Fru6P complex, involve Asp29 and residues of the Q-loop that contact Arg539\# and Glu535* of the neighboring synthase domain. This interaction, which is also conserved in the 
GImS.GIc6P.DON complex, is functionally relevant and allows to maintain the dimer interface during the hinge-rotation of the glutaminase domains that occurs during catalysis ${ }^{4}$. Given the existence of different copies of the GImS.Fru6P and GImS-GIc6P.DON structures in which the glutaminase domains are little and differently constrained, these structures can be directly compared to the rhombohedral structures in which the glutaminase domains are disordered. In fact, the mobility of the glutaminase domains observed in the rhombohedral crystal form is consistent with the analysis of the domain displacements in the TLS refinement of the GImS.Fru6P structure ${ }^{5}$. In the latter crystal, different directions of the libration axes for the three glutaminase domains in the asymmetric unit indicated individual displacements of these domains. In addition, a particularly large and anisotropic libration motion was observed for one of these domains.

Since the C-tail provides pockets for the aromatic groups of Tyr28 and Trp74 of the glutaminase domain in the GImS.Fru6P and GImS.DON.Glc6P structures ${ }^{4,8}$, it is not surprising that the glutaminase domains are disordered in the GImS structure in which the C-tail is disordered. In addition, crystallization of GImS alone in conditions that led to crystals of the GImS.Fru6P complex, in which the glutaminase domains are ordered, remained unsuccessful. Altogether, our results indicate that the closure of the synthase site likely precedes the ordering of the glutaminase domains. We propose that in solution, in the presence of cyclic sugar (Fru6P or GlcN6P), the glutaminase domains are also mobile, as observed in the rhombohedral crystal form.

The ordering of the glutaminase domains is linked to a conformational change of Ly $503^{\#}$ through a translational shift of helix CF.

Comparison of the GImS.Fru6P and GImS.GIcN6P structures indicates that, when the glutaminase domains become ordered, the positioning of the Trp74 indole group 
close to the synthase site is accompanied by a conformational change of Lys $503^{\#}$, due to steric hindrance (Fig. 4A). By interacting with the C-tail via four $\mathrm{H}$-bonds, the glutaminase domain also reinforces the position of the latter in the GImS.Fru6P structure (Fig. 4B). The maintenance of the salt bridge between Lys $503^{\#}$ and Glu535 comes with a translation of helix CF (residues 526-539) by one helix turn, which was previously noticed from the comparison of the structures of the whole enzyme and ${ }^{\mathrm{C}} \mathrm{GImS}{ }^{8}$. That way, when the glutaminase domains are ordered, Arg539\# at the end of helix CF makes new H-bonds with the carbonyl group of Ala75 of the Q-loop (residues 73-81 of the glutaminase domain) and the carboxylate group of Asp29 of loop 24-29. Thereby, these two loops, which are involved in the closing of the glutaminase site upon glutamine binding ${ }^{4}$, are maintained in an open conformation. While it is not clear what triggers the ordering of the glutaminase domains in GImS, this change is accompanied by a translation of helix CF of the synthase domain. Conformational changes upon acceptor binding involving not only the closure of the synthase site by a flexible loop but also the rearrangement of helices of the synthase domain have been observed for several glutamine amidotransferases ${ }^{13}$ such as glutamine phosphoribosylpyrophosphate amidotransferase ${ }^{14}$, pyridoxal-phosphate synthase ${ }^{15}$ or anthranilate synthase ${ }^{16}$.

\section{Sugar ring opening by catalytic His $504^{\#}$.}

The different conformations of Lys $503^{\#}$ are linked to different conformations of the His-loop backbone, which contains the flexible Gly505\#, and therefore to different positions of catalytic His504" (Fig. 4B). In the GImS.GlcN6P structure, the N $\delta$ group of $\mathrm{His} 504^{\#}$ makes $\mathrm{H}$-bonds both to the $\mathrm{C} 1$ hydroxyl and the endocyclic oxygen of the cyclic pyranose sugar. Since the GImS.GIcN6P structure corresponds to the catalytic 
conformation after ring closure of the product, this suggests that His $504^{\#}$ catalyzes the ring closure of linear GlcN6P. In the GImS.Fru6P structure, which corresponds to the catalytic conformation after the ring opening of the furanose substrate, His $504^{\#}$ makes a H-bond to the C5 hydroxyl group of the linear sugar (Fig. 4B). Modeling cyclic furanose Fru6P in the synthase site (data not shown) indicates that the $\mathrm{N} \delta$ group of His $504^{\#}$ is likely to make $\mathrm{H}$-bonds with the endocyclic oxygen and the $\mathrm{C} 2$ hydroxyl groups. Therefore, after hydrogen binding to the $\mathrm{C} 2$ hydroxyl group of cyclic Fru6P, His504 ${ }^{\#}$ can abstract the $\mathrm{O} 2$ hydrogen, open the ring and protonate $\mathrm{O} 5$ (Fig. 7 in $\left.{ }^{10}\right)$. In any case, after a cyclic sugar is bound, a conformational change of the Hisloop together with the ordering of the glutaminase domains contributes to move His504 ${ }^{\#}$ closer to the synthase site, which positions it in a correct position to open the sugar ring. The fact that the ordering of the glutaminase domains allows sugar ring opening by His $504^{\#}$ is supported by the presence of linear sugar in the synthase site of the GImS.Fru6P complex ${ }^{4,8}$, although cyclic Fru6P was used for crystallization.

\section{The linear sugar is deeply buried in the synthase site and completely shielded from solvent.}

Comparison of the structures of ${ }^{\mathrm{C}} \mathrm{GImS}$ and $\mathrm{GImS}$ in complex with different sugars shows that linear sugars are more deeply bound in the synthase site than cyclic sugars (Fig. 4C) and that increased interactions occur with linear compared to closed ligands (Table 2). The different binding mode of cyclic or linear sugars is linked to different conformations of the end of the C-loop and Lys $503^{\#}$ of the His-loop (Table 2, Fig. 4D). Actually, with a cyclic sugar, i. e. the conformation of the substrate in the first and last steps of catalysis corresponding to initial binding or final release of sugar, the C-tail covers the synthase site in a relaxed way, making direct contacts 
with the sugar but few interactions with the rest of the protein. The side-chain of Lys $503^{\#}$ adopts a completely different conformation of that adopted in the structures of GImS in complex with Fru6P or GIcN6P and DON, occupying the position of the absent indole group of Trp74 from the glutaminase domain (Fig. 4D). In fact, in the case of a cyclic sugar, this conformation of Lys $503^{\#}$ appears necessary to shield the synthase site from solvent, because the C-loop in its relaxed conformation does not complete shield it. With a linear sugar, which is the conformation of the sugar at the middle of the catalytic cycle, the synthase site is covered tightly by the C-loop. Indeed, the C-tail makes strong interactions with the rest of the protein, among which an important ionic interaction between the terminal carboxylate (residue 608) and Lys503", but interacts with the sugar through water molecules. It should be noted that this conformation of Lys $503^{\#}$ observed in the GImS.Fru6P and GImS.Glc6P.DON structures depends on the conformation of the sugar and not only on the presence of the glutaminase domains since the same conformation of Lys $503^{\#}$ is found in the structure of ${ }^{\mathrm{C}} \mathrm{GImS}$ in complex with linear 2-amino-deoxyglucitol-6P (Fig. 4D).

Actually, the conformational changes of the His-loop backbone and the side-chain of Lys503\#, which occur when the glutaminase domains become ordered, allow a deep burying of the newly-formed linear sugar inside the synthase binding pocket and a complete protection from solvent. This generates direct $\mathrm{H}$-bonds between the sugar and both the carboxylate group of Glu488 and the $\varepsilon$-amino group of Lys485 (Fig. 4D) 4. Glu488 and Lys485 were previously proposed to act as the catalytic bases which deprotonate $\mathrm{C} 1$ and the $\mathrm{O} 1$ hydroxyl group of linear Fru6P, respectively, during the sugar isomerization steps ${ }^{10}$, scheme 5 in ${ }^{17}$. In the present structures, these residues are positioned in a catalytically active conformation relative to the linear sugar. 


\section{Formation of the channel}

The walls of the ammonia channel are formed by the C-tail, the backbone of the Hisloop as well as the indole group of Trp74 and the main-chain of Arg26 from the glutaminase domain (Fig. 5). The backbone of the His-loop shows only minor structural changes during the catalytic cycle and is therefore already settled in the absence of sugar. Yet, because the C-tail is a major component of the ammonia channel, its disorder in the GImS structure demonstrates that the channel is not formed in the free enzyme. Sugar binding initiates the formation of the channel by ordering the C-tail. The channel is further shaped upon the ordering of the glutaminase domains through the positioning of the Trp74 and Arg26 main-chains. However, when the glutaminase site is empty, the indole group of Trp74 blocks the channel ${ }^{4,8}$. The channel is fully functional, connecting the glutaminase and synthase sites only upon glutamine binding, with the correct positioning of the Trp74 indole group, which forms an important part of its wall. The crucial role of Trp74 in ammonia channeling has been recently confirmed by mutagenesis studies ${ }^{18}$. Indeed, ammonia transfer that was abolished in the W74A mutant was partially restored by increasing the size of the side-chain of residue 74 .

\section{Conclusion}

Although more and more structures of glutamine amidotransferases in complex with different ligands have now been reported, there are only a few enzymes of this class for which different structures mimicking consecutive intermediates along the catalytic pathway have been determined ${ }^{13}$. The GImS and GImS.GIcN6P structures determined here can be compared to the previously reported GImS.Fru6P and GImS.GIc6P.DON structures ${ }^{4}$ to understand at the molecular level the different 
conformational changes occurring during catalysis. Several hints suggest that in the first and last steps of catalysis, corresponding to cyclic Fru6P binding and GlcN6P release, respectively, the glutaminase domains of free GImS remain flexible and that they order only once the C-tail has covered the synthase site. Indeed, first, the glutaminase domains are flexible in the GImS structure. Second, in the GImS.GIcN6P complex, the glutaminase domains are also mobile although the C-tail loop closes the synthase site. Third, a binding pocket for Trp74, which belongs to the glutaminase domain and forms the gate of the channel, is provided by the C-tail in its closed conformation.

The conformational changes accompanying sugar binding, leading to the opening of the sugar ring and the channel formation (Fig. 5), can be described as follows. In the absence of sugar, the C-tail and the glutaminase domains are not ordered and the synthase site is completely accessible to solvent. The His-loop carrying catalytic His504 ${ }^{\#}$ adopts a relaxed conformation distant from the synthase site of the neighboring monomer. Binding the cyclic sugar triggers the closure of the C-tail over the synthase site and the repositioning of His504 ${ }^{\#}$ nearer the synthase site. This initiates the formation of the channel with the C-tail forming its central portion. The ordering of the glutaminase domains follows and the positioning of Trp74 near the synthase site via its anchoring on the C-tail is accompanied by a complete rearrangement of Lys $503^{\#}$ together with a translational shift of helix CF, that strengthens the interactions between the C-tail and the synthase domain, resulting in the complete closure of the synthase site. The concomitant conformational change of the His-loop main-chain leads to the burying of the sugar inside the active site and the repositioning of His $504^{\#}$ in a fully catalytically active conformation, ready to open the sugar. The final constituents of the channel, Arg26 and Trp74 from the 
glutaminase domain are settled and the channel is formed, although blocked by the indole group of Trp74. Upon glutamine binding, rotation of the Trp74 indole group opens the channel and repositions Lys $503^{\#}$ to maintain its interaction with the C-tail so that the sugar remains completely buried ${ }^{4}$. After the reaction has proceeded and glutamate has been released, cyclization of the GlcN6P product occurs together with conformational changes of Lys $503^{\#}$ and of the glutaminase domains, which move away from the synthase domains. Finally, the opening of the synthase site through a conformational change of the C-loop enables the release of the cyclic GlcN6P product. The important conformational changes occurring during the first steps of catalysis, consisting in the binding and ring opening of cyclic Fru6P, and the final cyclization/release of GlcN6P through the ordering/disordering of the C-loop and the glutaminase domains, are in agreement with the formation of fructosimine-6P being rate-limiting and the cyclization/release of GIcN6P being slow ${ }^{19}$.

\section{Materials and methods}

GImS was purified as previously described ${ }^{4}$. Crystals were grown at $18^{\circ} \mathrm{C}$ in hanging-drops by vapor diffusion. For the GImS crystals, $1 \mu \mathrm{l}$ of the protein $\left(7 \mathrm{mg} \mathrm{ml}^{-1}\right.$ in $20 \mathrm{mM}$ HEPES $\mathrm{pH} 7.2,0.2 \mathrm{M} \mathrm{NaCl}$ ) was mixed with $1 \mu \mathrm{l}$ of a $1 \mathrm{ml}$ reservoir solution (7\% PEG 4000, $70 \mathrm{mM}$ sodium acetate $\mathrm{pH}$ 5.3, 30\% Glycerol). For the GImS.GIcN6P crystals, $1 \mu \mathrm{l}$ of a solution containing $7 \mathrm{mg} \mathrm{ml}^{-1}$ protein and $10 \mathrm{mg} \mathrm{ml}^{-1} \mathrm{GlcN} 6 \mathrm{P}$ in 20 mM HEPES pH 7.2, $0.2 \mathrm{M} \mathrm{NaCl}$ was mixed with $1 \mu \mathrm{l}$ of a $1 \mathrm{ml}$ reservoir solution ( $8 \%$ PEG 4000, $0.2 \mathrm{M}$ sodium acetate $\mathrm{pH}$ 5.5). Crystals grew to a size of $0.15 \mathrm{~mm} \times 0.15$ $\mathrm{mm} \times 0.15 \mathrm{~mm}$ in a few days. For the GImS.GIcN6P crystals, soaking was performed for a few minutes in a cryoprotectant solution (30\% glycerol, 12\% PEG 4000, $0.2 \mathrm{M}$ sodium acetate $\mathrm{pH} 5.5,5 \mathrm{mM}$ GlcN6P). Crystals were flash frozen in a cold nitrogen 
stream at $100 \mathrm{~K}$. The diffraction data sets were collected on beamline ID14-EH1 for the GlmS crystal or ID23-1 for the GImS.GlcN6P crystals at the European Synchrotron Radiation Facility (Grenoble) using an ADSC CCD detector. The data sets were processed with MOSFLM and SCALA ${ }^{20}$. Data processing statistics are reported in Table 1. Refinement was carried out with REFMAC5 ${ }^{21}$ starting from the model of ${ }^{\mathrm{C}} \mathrm{GImS}$ in complex with GlcN6P in $\mathrm{H} 32$ space group (PDB code 1MOQ). At the end of refinement, TLS parameters ${ }^{22}$ were refined using one TLS group for each sub-domain of the synthase domain (residues 243 to 449 and 450 to 608 for the GImS.GIcN6P structure or $450-601$ for the GImS structure).

To analyze the protein content of the crystals, several of them were harvested and submitted to four rounds of careful wash with stabilizing solution $(70 \mathrm{mM}$ sodium acetate $\mathrm{pH} 5.3,12 \%$ PEG 4000) followed by centrifugation at $10000 \mathrm{~g}$, to get rid of the protein remaining in solution. The crystals were finally dissolved in $20 \mathrm{mM}$ HEPES pH 7.3, $0.2 \mathrm{M} \mathrm{NaCl}$ and analyzed on a $10 \%$ acrylamide gel.

\section{Accession numbers.}

The coordinates and structure factors of the GImS and GImS.GlcN6P structures have been deposited at the Protein Data Bank (PDB codes 2vf4 and 2vf5, respectively).

\section{Acknowledgements.}

We thank Bernard Badet and Philippe Durand for critical reading of the manuscript.

\section{References}

1. Ghosh, S., Blumenthal, H. J., Davidson, E. \& Roseman, S. (1960). Glucosamine metabolism. V. Enzymatic synthesis of glucosamine 6-phosphate. J Biol Chem 235, 1265-73.

2. Badet, B., Vermoote, P. \& Le Goffic, F. (1988). Glucosamine synthetase from Escherichia coli: kinetic mechanism and inhibition by N3-fumaroyl-L-2,3diaminopropionic derivatives. Biochemistry 27, 2282-2287.

3. Vermoote, P. (1988). Thèse de l'Université Paris VI. 
4. Mouilleron, S., Badet-Denisot, M.-A. \& Golinelli-Pimpaneau, B. (2006). Glutamine binding opens the ammonia channel and activates glucosamine-6P synthase. J. Biol. Chem. 281, 4404-4412.

5. Mouilleron, S. \& Golinelli-Pimpaneau, B. (2007). Domain motions of glucosamine-6P synthase: comparison of the anisotropic displacements in the crystals and the catalytic hinge-bending rotation. Protein Sci 16, 485-93.

6. Storoni, L. C., McCoy, A. J. \& Read, R. J. (2004). Likelihood-enhanced fast rotation functions. Acta Crystallogr D Biol Crystallogr 60, 432-8.

7. Teplyakov, A., Obmolova, G., Badet-Denisot, M. A., Badet, B. \& Polikarpov, I. (1998). Involvement of the $C$ terminus in intramolecular nitrogen channeling in glucosamine 6-phosphate synthase: evidence from a 1.6 A crystal structure of the isomerase domain. Structure 6, 1047-1055.

8. Teplyakov, A., Obmolova, G., Badet, B. \& Badet-Denisot, M. A. (2001). Channeling of ammonia in glucosamine-6-phosphate synthase. J. Mol. Biol. 313, 1093-1102.

9. Scheringer, C. (1972). On the contributions of the internal modes of molecules to the Debye-Waller factors. Acta Cryst. A28, 516-522.

10. Teplyakov, A., Obmolova, G., Badet-Denisot, M. A. \& Badet, B. (1999). The mechanism of sugar phosphate isomerization by glucosamine 6-phosphate synthase. Protein Sci. 8, 596-602.

11. Golinelli-Pimpaneau, B. \& Badet, B. (1991). Possible involvement of Lys603 from Escherichia coli glucosamine-6-phosphate synthase in the binding of its substrate fructose 6-phosphate. Eur J Biochem 201, 175-82.

12. Raczynska, J., Olchowy, J., Konariev, P. V., Svergun, D. I., Milewski, S. \& Rypniewski, W. (2007). The Crystal and Solution Studies of Glucosamine-6phosphate Synthase from Candida albicans. J Mol Biol 372, 672-88.

13. Mouilleron, S. \& Golinelli-Pimpaneau, B. (2007). Conformational changes in ammonia-channeling glutamine amidotransferases. Curr Opin Struct Biol 17, 653-664.

14. Krahn, J. M., Kim, J. H., Burns, M. R., Parry, R. J., Zalkin, H. \& Smith, J. L. (1997). Coupled formation of an amidotransferase interdomain ammonia channel and a phosphoribosyltransferase active site. Biochemistry 36, 11061-11068.

15. Zein, F., Zhang, Y., Kang, Y. N., Burns, K., Begley, T. P. \& Ealick, S. E. (2006). Structural insights into the mechanism of the PLP synthase holoenzyme from Thermotoga maritima. Biochemistry 45, 14609-20.

16. Spraggon, G., Kim, C., Nguyen-Huu, X., Yee, M. C., Yanofsky, C. \& Mills, S. E. (2001). The structures of anthranilate synthase of Serratia marcescens crystallized in the presence of (i) its substrates, chorismate and glutamine, and a product, glutamate, and (ii) its end-product inhibitor, L-tryptophan. Proc Natl Acad Sci U S A 98, 6021-6.

17. Teplyakov, A., Leriche, C., Obmolova, G., Badet, B. \& Badet-Denisot, M. A. (2002). From Lobry de Bruyn to enzyme-catalyzed ammonia channelling: molecular studies of D-glucosamine-6P synthase. Nat. Prod. Rep. 19, 60-69.

18. Floquet, N., Mouilleron, S., Daher, R., Maigret, B., Badet, B. \& Badet-Denisot, M. A. (2007). Ammonia channeling in bacterial glucosamine-6-phosphate synthase (Glms): molecular dynamics simulations and kinetic studies of protein mutants. FEBS Lett 581, 2981-7.

19. Golinelli-Pimpaneau, B., Le Goffic, F. \& Badet, B. (1989). Glucosamine-6-phosphate synthase from Escherichia coli: Mechanism of the reaction at the fructose-6-phsophate binding site. J. Am. Chem. Soc. 111, 3029-3034.

20. Collaborative Computational Project Number 4. (1994). The CCP4 suite: programs for protein crystallography. Acta Crystallogr D Biol Crystallogr 50, 760-3. 
21. Murshudov, G. N., Vagin, A. A. \& Dodson, E. J. (1997). Refinement of macromolecular structures by the maximum-likelihood method. Acta Crystallogr D Biol Crystallogr 53, 240-55.

22. Winn, M. D., Isupov, M. N. \& Murshudov, G. N. (2001). Use of TLS parameters to model anisotropic displacements in macromolecular refinement. Acta Crystallogr. D 57, 122-133. 


\section{Figure legends}

\section{Figure 1}

The glutaminase domains are present but disordered in the GImS and GImS.GIcN6P structures.

A: Molecular packing of the GImS crystal. The asymmetric unit contains one monomer, constituted by one synthase domain and one glutaminase domain that is not observed in the electron density. The interface of the functional dimer is formed by two synthase domains (colored in blue and cyan) belonging to neighboring asymmetric units. The $\mathrm{N}$-terminal residues of the synthase domains is indicated for one dimer. A large volume in which no model could be traced can accommodate the glutaminase domain.

B: SDS-PAGE analysis (10\% gel) of dissolved crystals of GImS. Lanes 1 and 4: different molecular weight markers; lane 2: purified GImS before crystallization (2.6 $\mu \mathrm{g})$; lane 3: dissolved crystals of GImS $(2.15 \mu \mathrm{g})$.

\section{Figure 2:}

TLS refinement of the GImS and GImS.GIcN6P structures with two sub-domains of ${ }^{\mathrm{C}}$ GImS being treated as different TLS groups.

A The $\mathrm{C} \alpha$ trace of ${ }^{\mathrm{C}} \mathrm{GImS}$ of the GlmS structure is colored according to the isotropic B-factors ranging from dark blue $\left(B=25 \AA^{2}\right)$ to red $\left(B=110 \AA^{2}\right)$.

B Comparison of the displacement parameters of ${ }^{\mathrm{C}} \mathrm{GImS}$ before and after the anisotropic refinement. Up: GImS crystal. Down: GImS.GlcN6P crystal. B $B_{\text {TLS, the }}$ contribution from the TLS motion, $B_{\text {res, }}$, the residual $B$ factors after applying the TLS

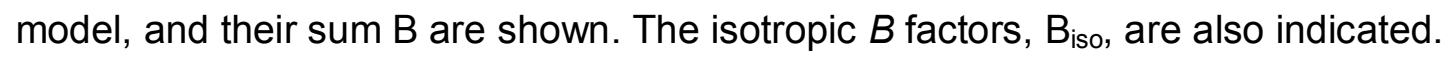

C Mean displacements given as the TLS tensor eigenvalues, when each subdomain 
of the synthase domain is treated as a rigid group in the TLS refinements. Group 1 includes residues 243 to 449 and group 2, residues 450 to 608 .

Left: GImS structure, right: GImS.GIcN6P structure

A Eigenvalues of the translation tensor.

B Eigenvalues of the libration tensor

C Eigenvalues of the screw tensor

The eigenvalues are shown as a cumulative stack bar. The $\mathrm{S}$ tensor was made symmetric by referring it to a coordinate system whose origin is at the center of reaction for the rigid group.

Figure 3: In the absence of sugar, the C-tail is disordered and the synthase is accessible to solvent.

A: A 2|Fol-|Fcal| electron density map contoured at $1 \sigma$ shows no density for residues 602 to 608 of the C-tail in the GImS structure, which indicates its disorder. Two synthase domains (stick models in yellow and orange) belonging to neighboring asymmetric units form an extensive interface. In the Glms.GlcN6P structure (synthase domains in pink and magenta coils), the C-loop covers the GlcN6P product (sphere model) in the synthase site.

B Synthase site of the GImS.GlcN6P structure showing the GlcN6P ligand and residues distant less than $4 \AA$. A $2 \mid$ Fol-|Fcal| electron density map contoured at $1 \sigma$ is superimposed on the model.

C: General view of the sugar-binding site.

The synthase active site is formed at the interface of two synthase domains belonging to different monomers (in dark and light blue). When both the synthase and glutaminase domains are ordered as in the GImS.Fru6P structure ${ }^{4}$ (glutaminase 
domain in cyan), the C-loop (in red) is sandwiched between one synthase domain and one glutaminase domain of the same monomer. The sugar-binding site is made by the backbones of the His-loop (in green) and C-loop. The Trp74 indole group from the glutaminase domain also participates in shielding the synthase site from solvent. The opening of the synthase site may result from a movement of the C-tail, the Hisloop and/or the glutaminase domain.

Figure 4: Conformational changes linked to the ordering of the glutaminase domains. The synthase domains are indicated in yellow and orange, pink and magenta light and dark blue and light and dark green for the GImS, GImS.GIcN6P, GImS.Fru6P and GImS.GIc6P.DON structures, respectively. The glutaminase domains of the GImS.Fru6P and GImS.Glc6P.DON structures are indicated in cyan and green, respectively.

A The ordering of the glutaminase domains is accompanied by a conformational change of Lys $503^{\#}$ and a translation shift of helix CF. In the GImS.Fru6P structure, the $\mathrm{H}$-bonds that Arg539\# makes with the carboxyl group of Asp29 and the carbonyl group of Ala75 ensure the contact between the glutaminase and synthase domains of different monomers. In the GImS.GIcN6P and GImS structures, Arg539\# H-binds to the carbonyl group of lle $510^{\#}$ (not shown) and to the side-chain carbonyl group of Asn600. The salt bridge between the $\varepsilon$-amino group of Lys $503^{\#}$ and the oxygen carboxylate of Glu535 ${ }^{\#}$ is conserved in all structures through the translation of helix CF. In addition, Lys $503^{\#} \mathrm{H}$-binds to the main-chain carbonyl group of Asn600 in the GImS.GIcN6P and GImS structures but to the terminal carboxyl group of Glu608 in the GImS.Fru6P structure. 
B Closer view of the synthase site showing the interactions between the C-tail and the synthase domain of the same monomer, the sugars and the glutaminase domains. Whereas the C-tail is disordered in the GImS structure, in the GImS.Fru6P structure, it is linked to the synthase domain of the same monomer via H-bonds between the carbonyl group of Val605 and the $\mathrm{NH}$ group of Ala353, between the $\varepsilon$ amino group of Lys603 and both the carbonyl group of Gly398 and the carboxylate of Glu396, and between the side-chain carboxylate of Glu608 and the hydroxyl group of Tyr332. Most of these interactions are also observed in the GImS.GlcN6P structure. In the GImS.Fru6P structure, the glutaminase domain and the C-loop are linked by four H-bonds, between the hydroxyl group of Tyr28 and the carbonyl group of Leu601, the carbonyl group of Tyr25 and NH group of Lys603, the guanidinium group of Arg26 and both the carbonyl group of Lys603 and the hydroxyl group of Thr606. In the GImS, GImS.GIcN6P and GImS.Fru6P structures, containing respectively no sugar, a cyclic sugar or a linear sugar, the location of His504 ${ }^{\#}$ is different. The imidazole $\mathrm{N} \delta$ of His504 ${ }^{\#} \mathrm{H}$-binds to the hydroxyl 01 atom of GlcN6P and to the hydroxyl 05 atom of Fru6P. The $\mathrm{H}$-bonds between the sugar and the catalytic residues Lys 485 and Glu488 are direct for the GImS.Fru6P structure but mediated by water molecules for the GImS.GIcN6P structure. There are two direct H-bonds between the C-tail and GlcN6P (through the carbonyl oxygen atom of Ala602 and both hydroxyl 01 and the amino group of GlcN6P), while all the contacts between the C-tail and Fru6P are indirect.

C View of a molecular surface section of the sugar-binding pocket in the GImS.GIcN6P structure. Open-chain Fru6P (in blue stick) lies deeper in the sugarbinding pocket than cyclic GlcN6P (in pink stick). When sugar is bound at the synthase site, the C-tail (in coil) covers the synthase site. 
D Lys503 ${ }^{\#}$ adopts very different conformations in the complexes with linear or cyclic sugars. In the structures of GImS.Fru6P, GImS.GIc6P.DON and ${ }^{\mathrm{C}} \mathrm{GImS} \cdot 2$-amino-2deoxy-glucitol-6P structures (synthase domains in dark and light gray), the $\varepsilon$-amino group of Lys $503^{\#}$ makes an ionic interaction with the carboxylate of the terminal amino acid (residue 608 of the C-loop), thereby strengthening the interactions between the $\mathrm{C}$-tail and the synthase domain. Moreover, the conformation of the Hisloop main-chain allows a deeper burying of the sugar inside the synthase site, which is completely inaccessible to solvent. In the structures of GImS and GImS.GIcN6P structures, the C-loop is in a relaxed conformation and Lys $503^{\#}$ participates in shielding the synthase site from solvent in the absence of ordered glutaminase domain.

\section{Figure 5:}

Step by step formation of the ammonia channel. The accessible surface in the different structures calculated with PYMOL and a probe of $1.3 \AA$ radius is represented following the same color scheme as figure 4 and is superposed to the accessible surface of the channel in the GImS.GIc6P.DON structure, represented as a grey mesh surface. The positions of GIc6P and DON as observed in the GImS.Glc6P.DON structure are indicated in grey to locate the synthase and glutaminase sites in all structures. A GImS structure. The glutaminase domain and the C-loop are not ordered and the synthase site is open to solvent. The channel is not formed because only the His-loop forms one of its rim. B: GImS.GIcN6P structure. In the presence of cyclic sugars, the C-loop is in a relaxed conformation and Lys503\# participates in shielding the synthase site from solvent in the absence of ordered glutaminase domains. C: GImS.Fru6P structure. Because of the ordering of 
the glutaminase domains, the channel is almost formed but not continuous because the indole group of Trp74 is inserted between the two observed adjacent cavities. D: GImS.GlcN6P structure. The rotation of the Trp74 indole group opens the channel, which is fully functional. 
Table 1: Data collection and refinement statistics.

\begin{tabular}{|c|c|c|}
\hline & GlmS & GlmS.GlcN6P \\
\hline \multicolumn{3}{|l|}{ Data collection } \\
\hline Space Group & $\mathrm{H} 32$ & H32 \\
\hline Cell dimensions a, b, c ( $)$ & $144.7,144.7,171.7$ & $144.7,144.7,171.4$ \\
\hline$\alpha, \beta, \gamma\left(^{\circ}\right)$ & $90,90,120$ & $90,90,120$ \\
\hline Resolution $(\AA)$ & $20.00-2.95$ & $20.00-2.90$ \\
\hline Outer resolution shell ( $\AA$ ) & $3.11-2.95$ & $3.06-2.90$ \\
\hline $\mathrm{N}^{\circ}$ unique reflections & 13948 & 15522 \\
\hline $\mathrm{R}_{\text {sym }}$ & $0.10(0.48)$ & $0.084(0.51)$ \\
\hline $\mathrm{I} / \mathrm{I} \sigma$ & $6.3(1.6)$ & $5.3(1.5)$ \\
\hline Completeness (\%) & $99.8(99.8)$ & $99.2(99.2)$ \\
\hline Redundancy & $7.2(7.3)$ & $4.6(4.7)$ \\
\hline \multicolumn{3}{|l|}{ Refinement } \\
\hline No. reflections & 13874 & 14581 \\
\hline \multicolumn{3}{|l|}{ Isotropic Refinement } \\
\hline Resolution $(\AA)$ & $15.0-2.95$ & $15.0-2.90$ \\
\hline (Outer resolution shell) $(\AA)$ & $3.11-2.95$ & $3.06-2.90$ \\
\hline $\mathrm{R}_{\text {free }}(\%)$ & $29.84(42.2)$ & $26.92(37.1)$ \\
\hline $\mathrm{R}(\%)$ & $23.60(29.3)$ & $22.01(30.5)$ \\
\hline \multicolumn{3}{|l|}{ TLS Refinement } \\
\hline Resolution $(\AA)$ & $15.00-2.95$ & $15.00-2.90$ \\
\hline (Outer resolution shell) $(\AA)$ & $3.02-2.95$ & $2.97-2.90$ \\
\hline $\mathrm{R}_{\text {free }}(\%)$ & $25.7(30.5)$ & $24.2(29.1)$ \\
\hline $\mathrm{R}(\%)$ & $21.8(23.2)$ & $21.7(23.8)$ \\
\hline \multicolumn{3}{|l|}{$\begin{array}{l}\text { Average B-factors } \\
\text { (before TLS / after TLS) }\end{array}$} \\
\hline Protein & $62.7 / 17.0$ & $70.3 / 27.3$ \\
\hline Ligand & - & $60.0 / 24.8$ \\
\hline Water & $43.2 / 49.5$ & $50.9 / 54.0$ \\
\hline \multicolumn{3}{|l|}{ No. atoms } \\
\hline Protein & 2774 & 2825 \\
\hline Ligand & - & 16 \\
\hline Water & 11 & 12 \\
\hline \multicolumn{3}{|l|}{ rmsd } \\
\hline Bond lengths $(\AA)$ & 0.02 & 0.02 \\
\hline Bond angles $\left({ }^{\circ}\right)$ & 2.31 & 2.12 \\
\hline \multicolumn{3}{|l|}{ Ramachandran statistics (\%) } \\
\hline Most favored & 80.9 & 80.7 \\
\hline Additionally allowed & 17.2 & 18.4 \\
\hline Generously allowed & 1.9 & 0.6 \\
\hline Disallowed & 0 & 0.3 \\
\hline $\begin{array}{l}\text { Estimated overall coordinate error } \\
\text { based on maximum lilkelihood }(\AA)\end{array}$ & 0.28 & 0.24 \\
\hline
\end{tabular}


Table 2: Links between the sugar conformation, the presence of the glutaminase domains and the postions of Lys503" , the C-tail and helix CF. 'SB: Number of salt bridges, HB: number of hydrogen bonds.

\begin{tabular}{|c|c|c|c|c|c|c|c|}
\hline & $\begin{array}{l}\text { Domaine } \\
\text { glutaminase }\end{array}$ & $\begin{array}{c}\text { Sugar } \\
\text { conformation }\end{array}$ & C-tails & $\begin{array}{l}\text { Interactions } \\
\text { between } \\
\text { residues } \\
608 \text { or } 602- \\
607 \text { of the } \\
\text { C-tail and } \\
\text { the protein }\end{array}$ & $\begin{array}{l}\text { Interactions } \\
\text { between the } \\
\text { C-tail and } \\
\text { the sugar }\end{array}$ & $\begin{array}{l}\text { Position } \\
\text { of Lys } 503^{\#} \\
\text { relative to the } \\
\text { synthase site }\end{array}$ & Helix CF \\
\hline GlmS.Fru6P & $\begin{array}{c}\text { ordered } \\
\text { open site }\end{array}$ & Linear & $\begin{array}{l}\text { Structured } \\
\text { (Completely } \\
\text { closed) }\end{array}$ & $\begin{array}{c}1 \mathrm{SB}+2 \mathrm{HB} / \\
6 \mathrm{HB}^{1}\end{array}$ & 0 & $\begin{array}{c}\text { Conformation } \\
2 \\
\text { (SB E535) } \\
\text { (SB E608- } \\
\text { Cter) }\end{array}$ & Translated \\
\hline $\begin{array}{l}\text { GlmS.Glc6P } \\
\text { ·DON }\end{array}$ & $\begin{array}{l}\text { ordered } \\
\text { closed site }\end{array}$ & Linear & $\begin{array}{l}\text { Structured } \\
\text { (Completely } \\
\text { closed) }\end{array}$ & $6 \mathrm{HB} / 6 \mathrm{HB}$ & 0 & $\begin{array}{c}\text { Conformation } \\
3 \\
\text { (SB E535) } \\
\text { (HB N600) }\end{array}$ & Translated \\
\hline $\begin{array}{c}{ }^{{ }^{\mathrm{C}} \mathrm{GlmS} \cdot 2 \mathrm{ami}} \\
\text { no-glucitol- } \\
6 \mathrm{P}\end{array}$ & Not present & Linear & $\begin{array}{l}\text { Structured } \\
\text { (Completely } \\
\text { closed) }\end{array}$ & $3 \mathrm{HB} / 2 \mathrm{HB}$ & 0 & $\begin{array}{c}\text { Conformation } \\
2\end{array}$ & Relaxed \\
\hline $\begin{array}{c}{ }^{\mathrm{C}} \text { GlmS.Glc6 } \\
\mathrm{P}\end{array}$ & Not present & Cyclic & $\begin{array}{l}\text { Structured } \\
\text { (partially } \\
\text { closed) }\end{array}$ & $\begin{array}{c}0 / 3 \mathrm{HB} \\
(+1 \text { with } \\
\text { Glc6P) }\end{array}$ & $2 \mathrm{HB}$ & $\begin{array}{c}\text { Conformation } \\
1\end{array}$ & Relaxed \\
\hline $\begin{array}{c}\text { GlmS·GlcN6 } \\
\text { P }\end{array}$ & Mobile & Cyclic & $\begin{array}{l}\text { Structured } \\
\text { (partially } \\
\text { closed) }\end{array}$ & $\begin{array}{c}0 / 3 \mathrm{HB} \\
(+2 \text { with } \\
\text { GlcN6P) }\end{array}$ & $1 \mathrm{HB}$ & $\begin{array}{c}\text { Conformation } \\
1\end{array}$ & Relaxed \\
\hline GlmS alone & Mobile & - & $\begin{array}{l}\text { Mobile } \\
(602-608)\end{array}$ & 0 & - & $\begin{array}{c}\text { Conformation } \\
1 \\
\text { (HB E535) }\end{array}$ & Relaxed \\
\hline
\end{tabular}


Figure 1

Figure 1

A
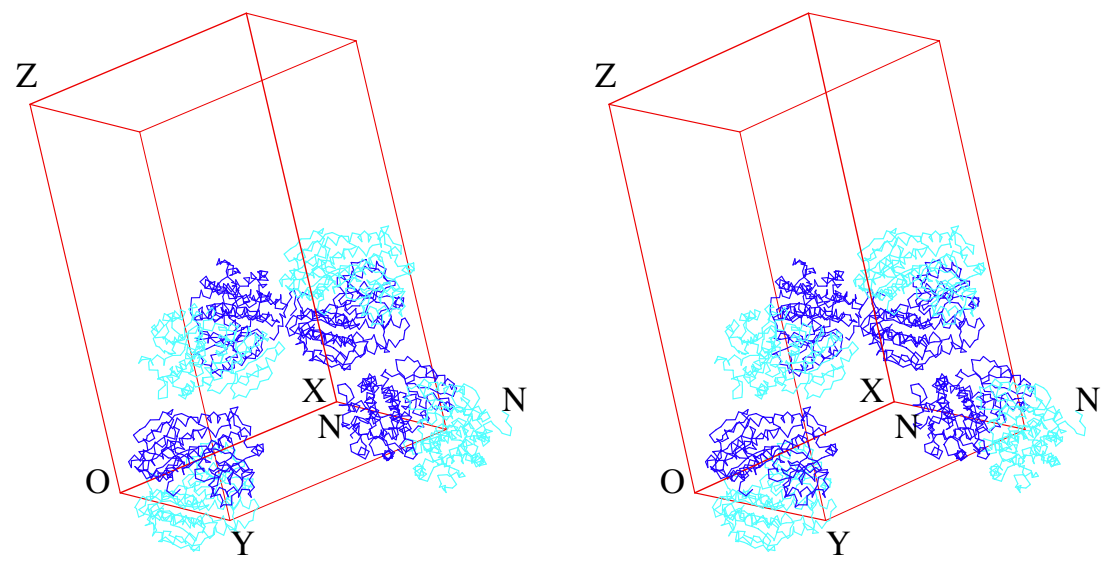

B

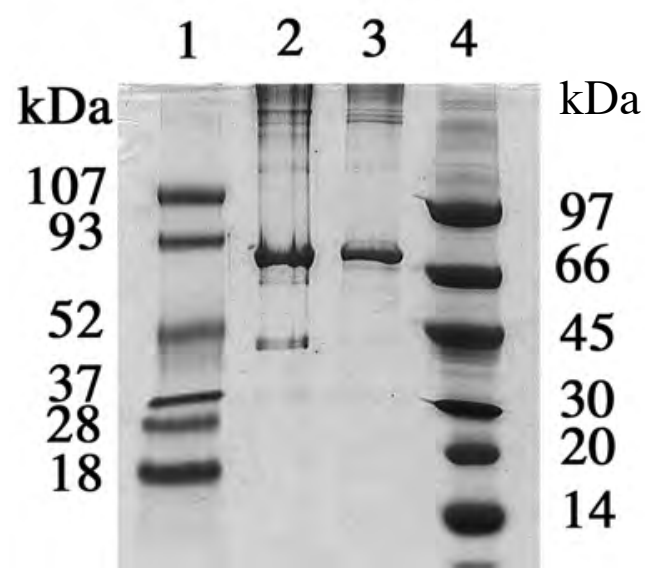


Figure 2

Figure 2

A

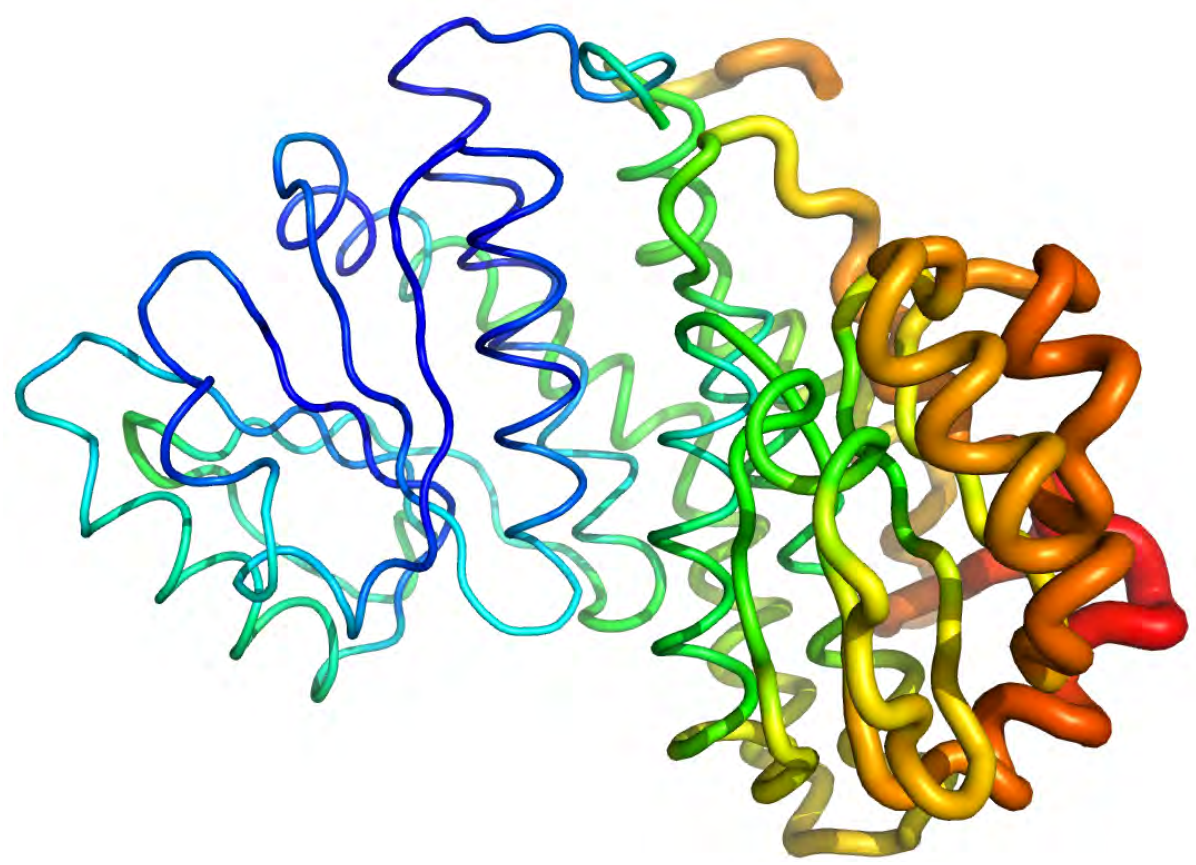

B
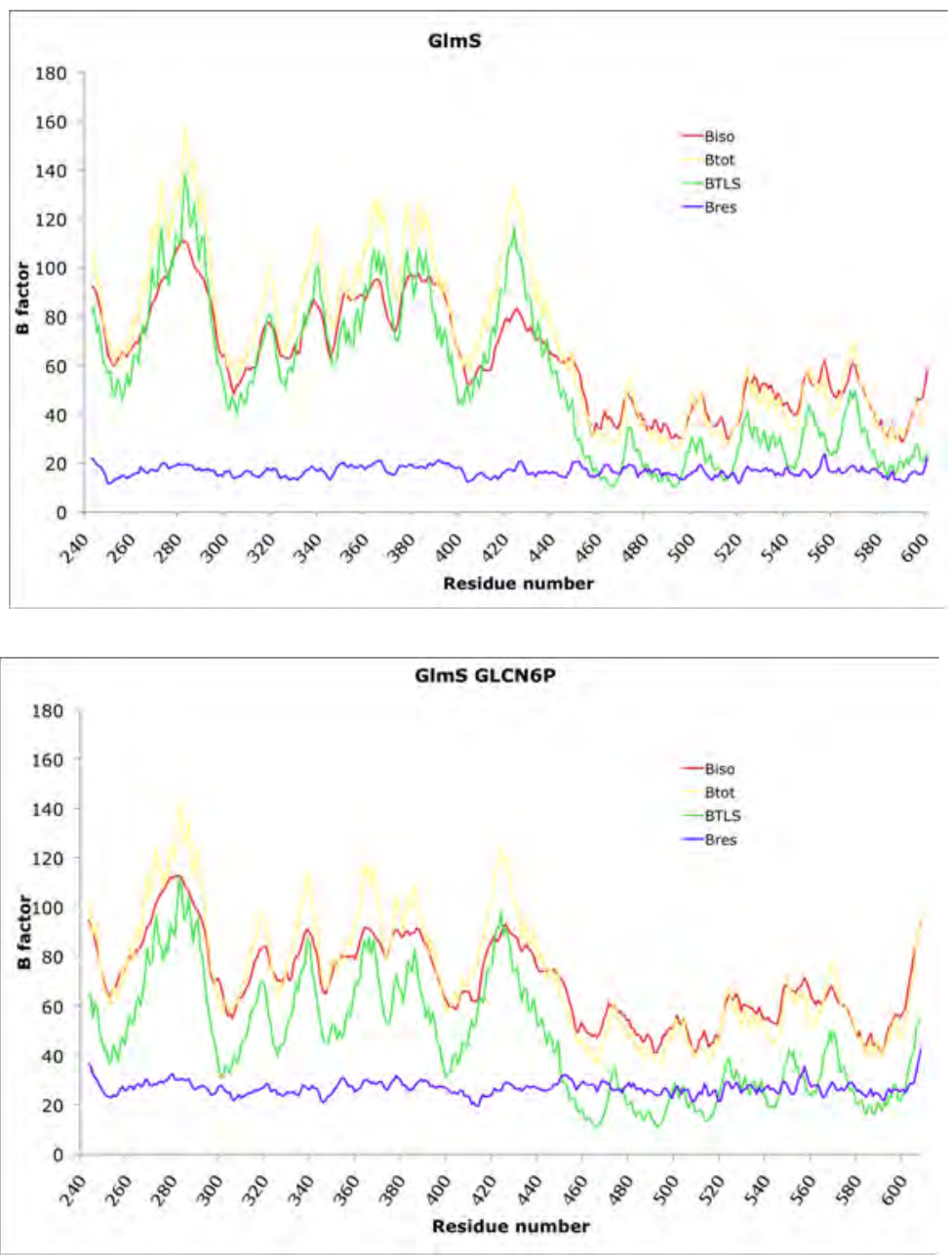

C
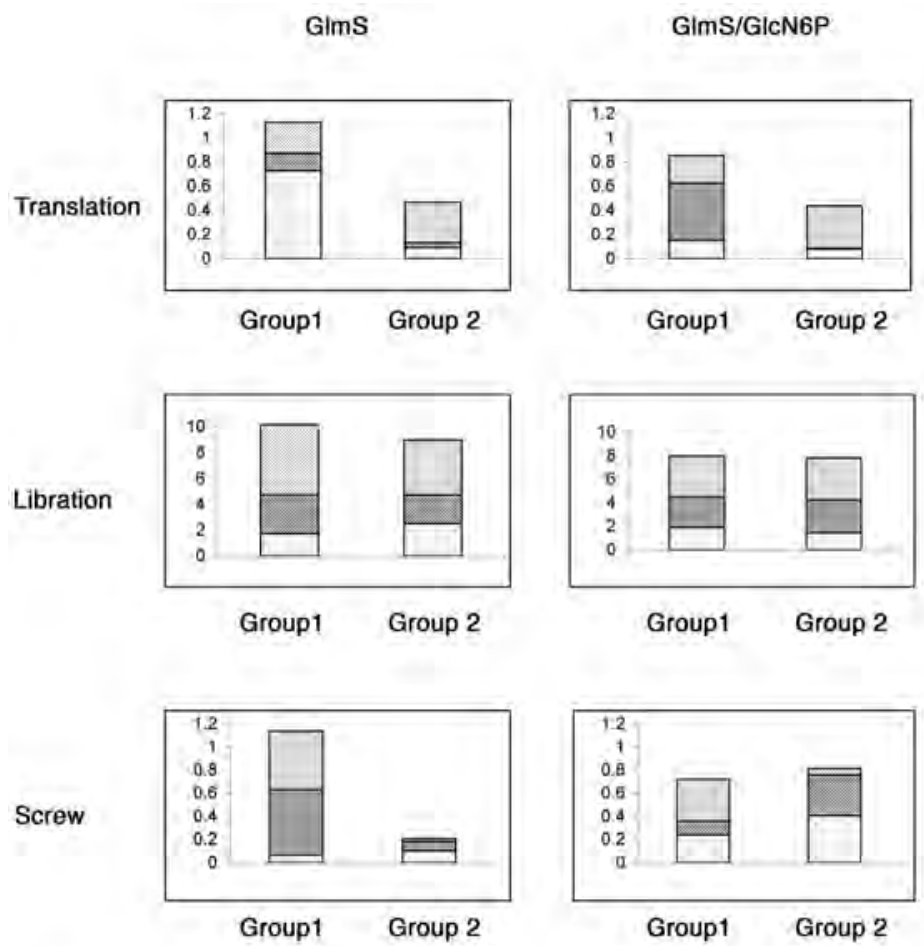

Group $1=243-449$ Group2 $=450-608$ 
Figure 3

A

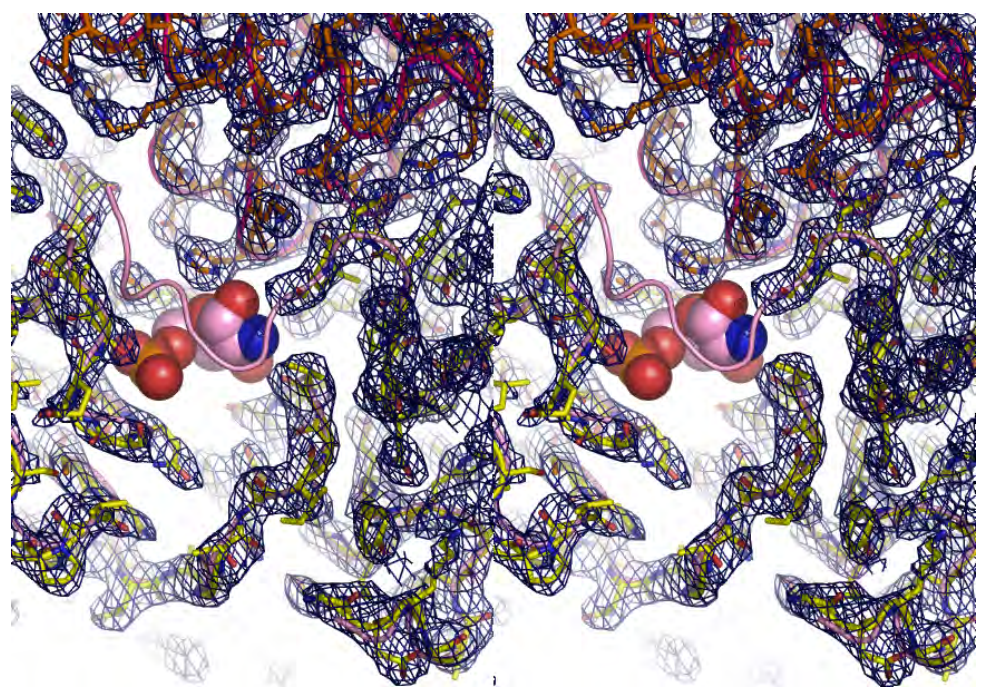

B

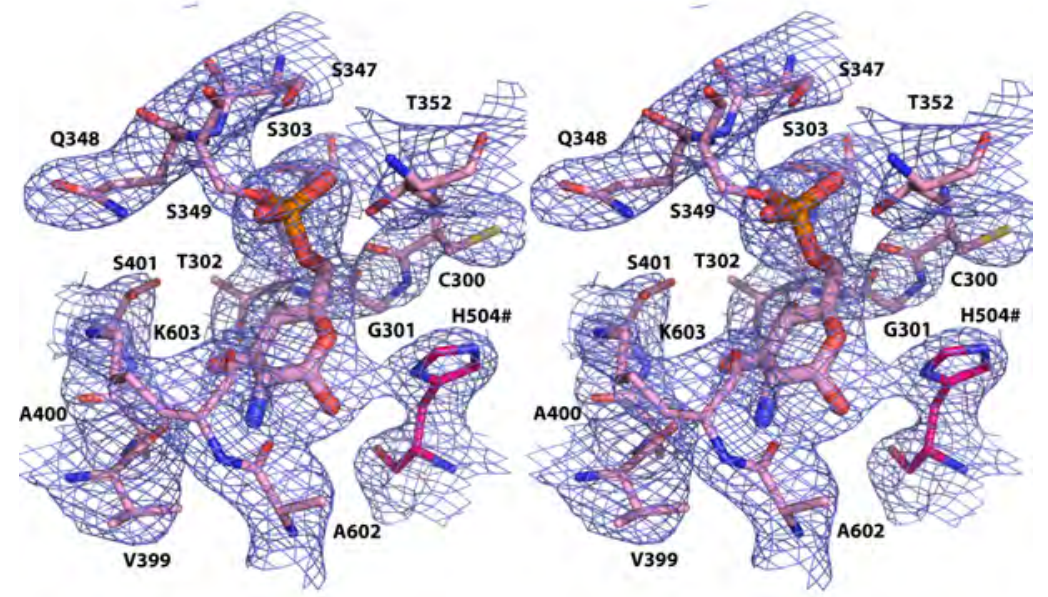

C

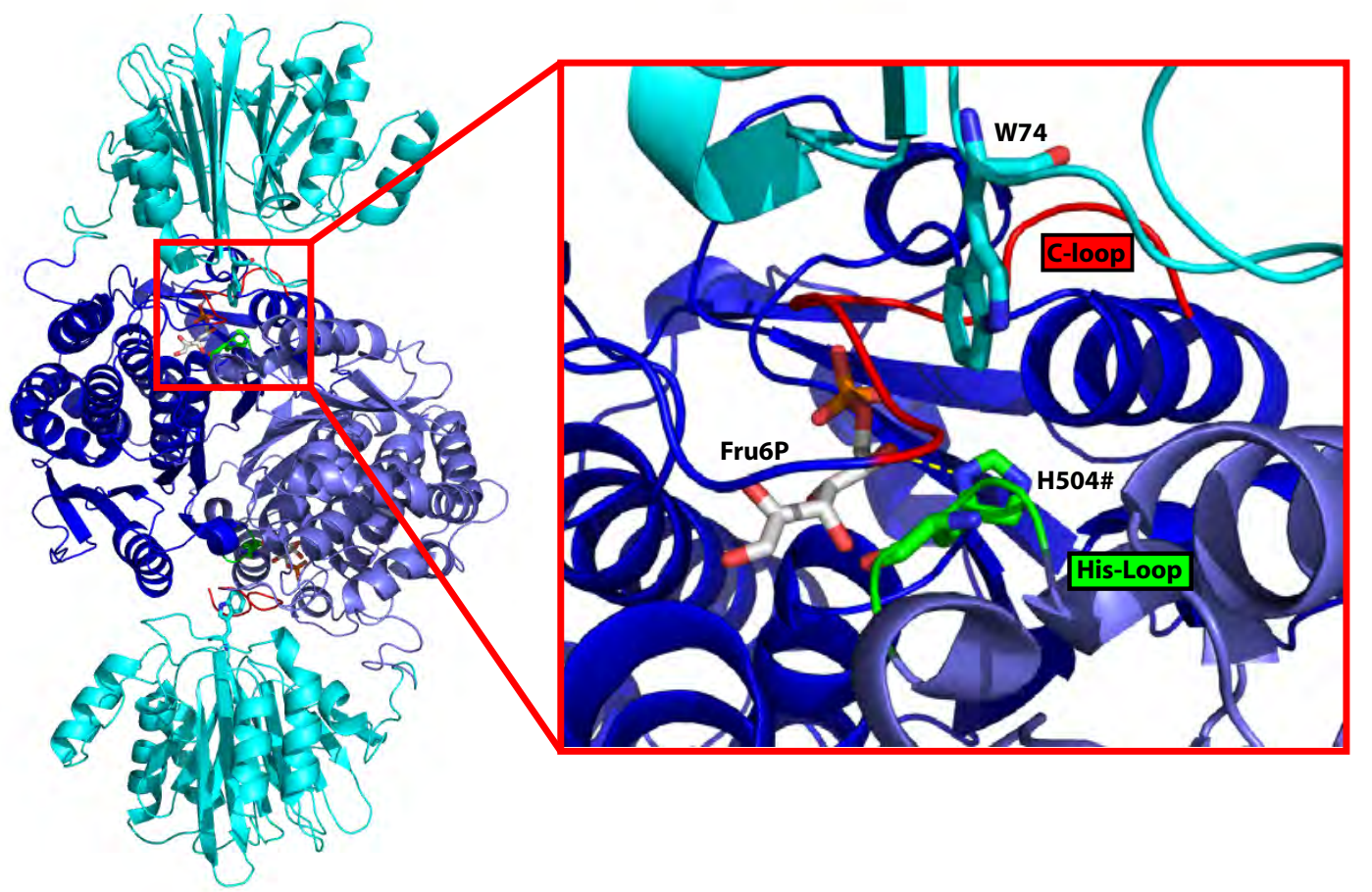


Figure 4
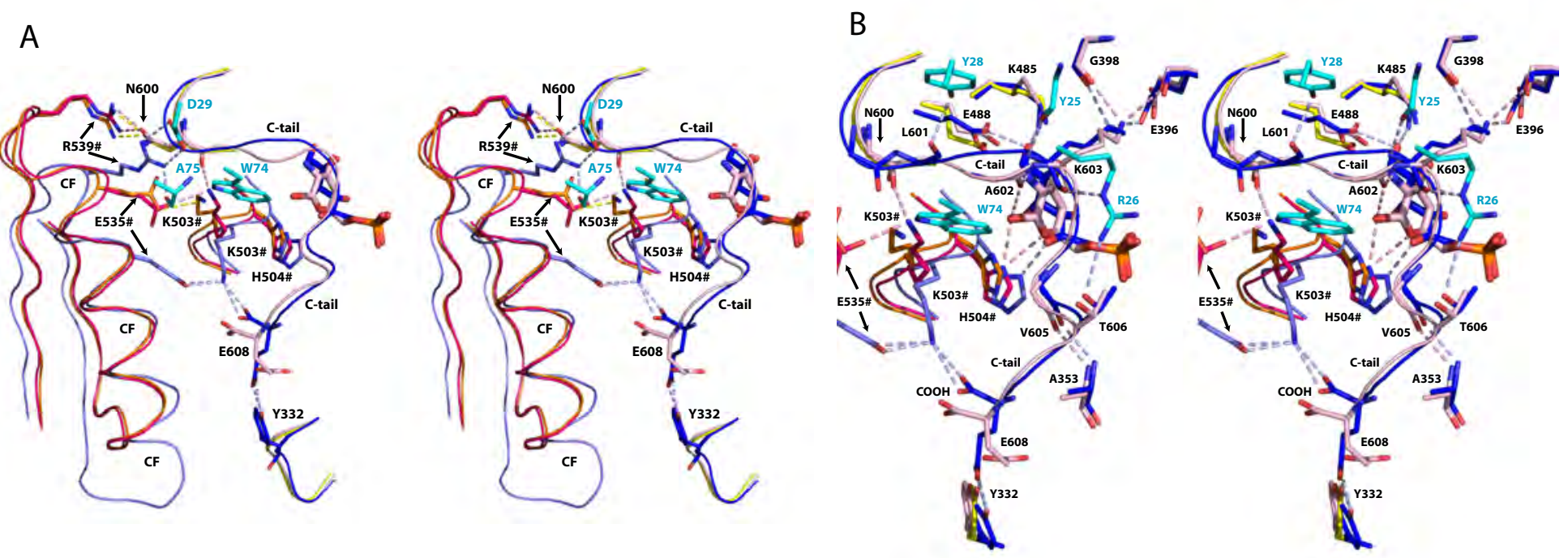

D
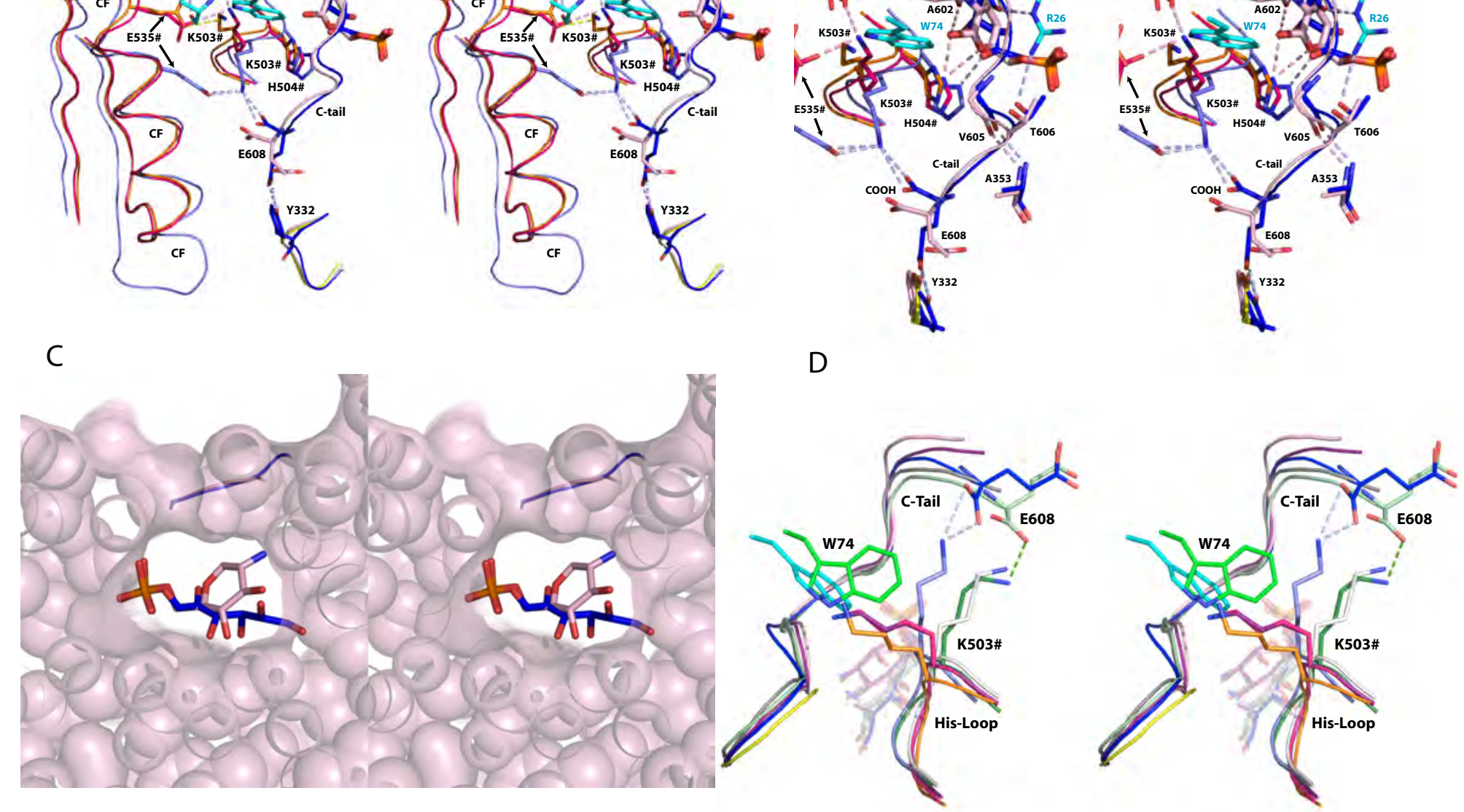
Figure 5

Figure 5

A

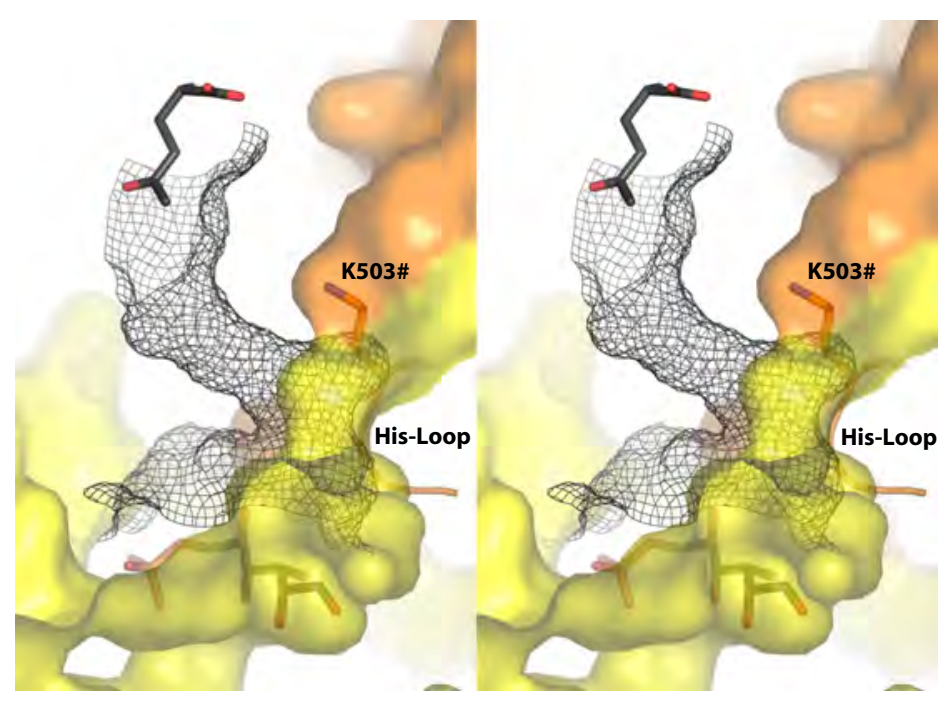

C

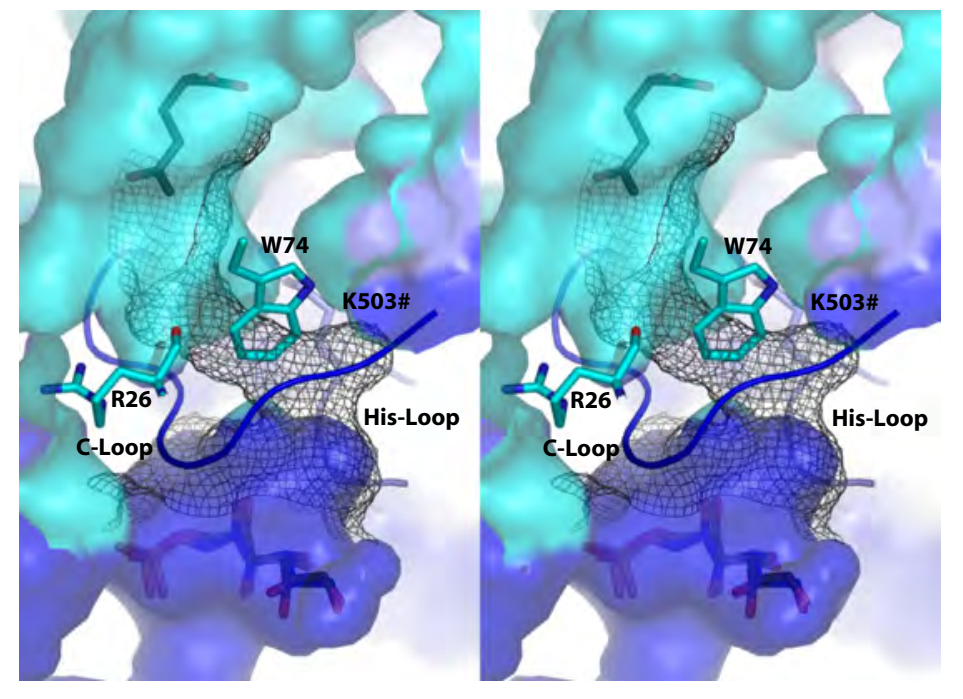

B

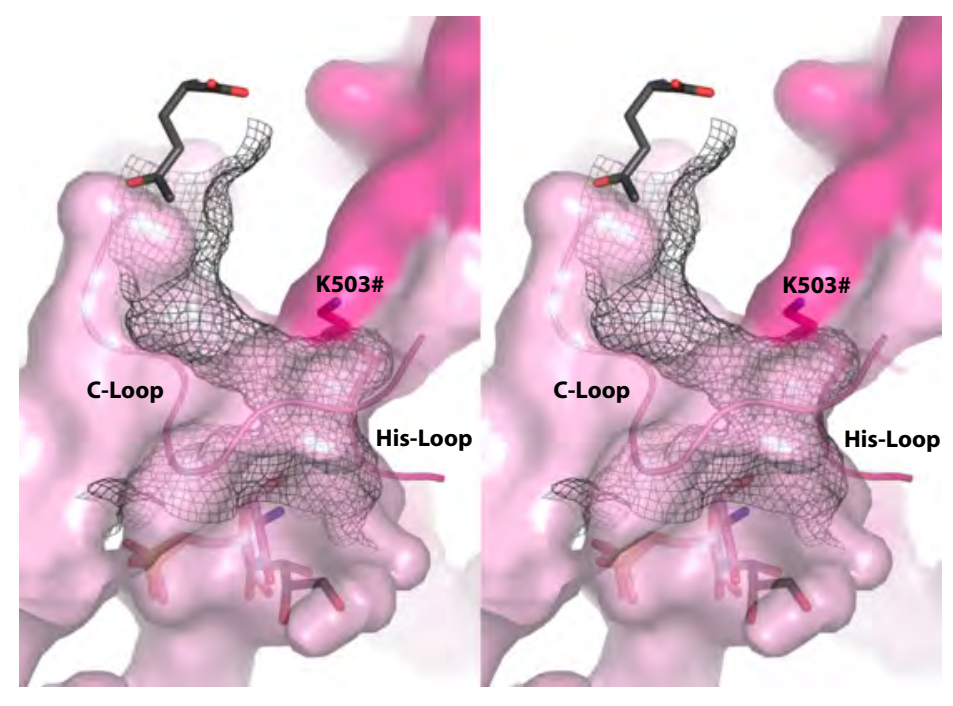

D

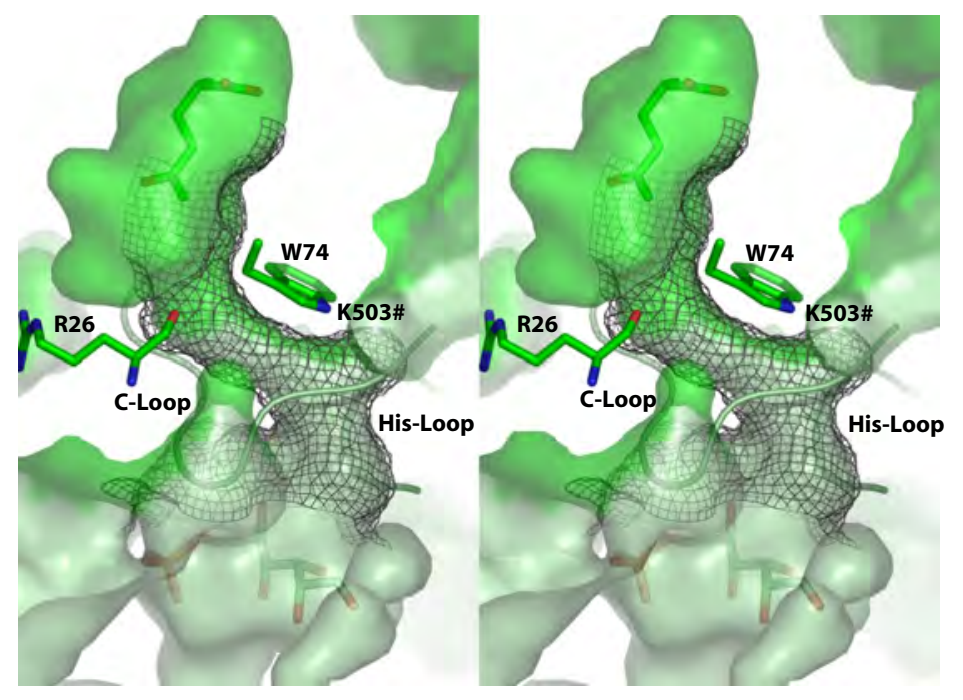

